\title{
Het vaststellen van fysieke activiteit van volwassenen uit 11 landen tijdens de COVID-19 pandemische lockdown
}

\author{
Koen J. M. Spaninks
}

Published online: 11 februari 2022

(c) Bohn Stafleu van Loghum is een imprint van Springer Media B.V., onderdeel van Springer Nature 2022

\begin{abstract}
Samenvatting Deze studie beschrijft de fysieke activiteit van 11.775 volwassen uit 11 landen tijdens de COVID-19-lockdown en onderzocht factoren die verband houden met fysieke activiteit. Meer dan $40 \%$ van de deelnemers was onvoldoende lichamelijk actief voor de lockdown en meer dan $44 \%$ rapporteerde een verminderde fysieke activiteit tijdens de lockdown. Deze verschillen waren statistisch-significant in vergelijking met de periode voor de lockdown. Ook het niveau van fysieke activiteit was tijdens de lockdown significant verminderd. Strengere overheidsmaatregelen en hogere depressie- en angstscores resulteerden in minder fysieke activiteit. Uit dit onderzoek werd geconcludeerd dat tijdens een lockdown en vergelijkbare globale noodsituaties het nodig is om mensen aan te sporen tot fysieke activiteit.
\end{abstract}

Trefwoorden verandering in fysieke activiteit . COVID-19-pandemische lockdown

In deze rubriek vat de auteur een internationaal gepubliceerd onderzoek samen en geeft een beschouwing op dat onderzoek. In deze editie betreft het het artikel: Kele Ding, Jingzhen Yang, Ming-Kai Chin, Lindsay Sullivan, J. Larry Durstine, Verónica Violant-Holz, Giyasettin Demirhan, Nara R.C. Oliveira, Biljana Popeska, Garry Kuan, Waheeda Khan, Jianhui Dai, Xia Xu, Zornitza Mladenova, Govindasamy Balasekaran, Gary A. Smith and on behalf of Global Community Health-COVID-19 Collaborative Research Team. Physical activity among adults residing in 11 countries during the COVID-19 pandemic lockdown. Int J Environ Res Public Health. 2021;18(13):7056. https://doi. org/10.3390/ijerph18137056 (open source).

K. J. M. Spaninks, BSc ( $₫)$

Podotherapie het Gooi, Bussum, Nederland

koenspaninks@hotmail.com

\section{Inleiding}

In het hier besproken onderzoek is de fysieke activiteit vastgesteld bij volwassenen tijdens de COVID-19lockdown in 11 landen.

\section{Samenvatting van het oorspronkelijke artikel}

\section{Inleiding}

De wereldwijde uitbraak van het coronavirus heeft geleid tot 'lockdowns', een 'blijf-thuisbeleid' en 'social distancing'[1]. Deze hebben een negatieve invloed op de fysieke en mentale gezondheid van individuen over de hele wereld, die voornamelijk te wijten is aan de onzekerheid over het virus, als ook aan stress en eenzaamheid door sociale isolatie vanwege de lockdown [2]. Onder deze omstandigheden is dagelijkse fysieke activiteit belangrijker dan ooit, omdat fysieke activiteit bekend staat als middel om een goede fysieke en mentale gezondheid te behouden[3]. De Wereldgezondheidsorganisatie (WHO) adviseert volwassenen tussen de 18 en 65 jaar elke week minstens 150 minuten licht intensief of 75 minuten fors intensief fysiek actief te zijn [4].

De studie die in dit artikel wordt besproken, beschrijft fysieke activiteit bij volwassenen $\geq 18$ jaar uit 11 landen tijdens lockdown en onderzoekt factoren die verband houden met die fysieke activiteit. Nagegaan is wat het verband is tussen het landelijke COVID-19-risiconiveau (een oplopend aantal besmettingen in relatie tot het overheidsbeleid), negatieve symptomen op het gebied van mentale gezondheid (depressie en angst), demografische factoren, het niveau waarop fysieke activiteit plaatsvindt en veranderingen in de hoeveelheid fysieke activiteit tijdens de COVID-19-lockdown, waar die fysieke activiteit plaatsvindt en de wijze waarop. 


\section{Methode}

\section{Studieontwerp en deelnemers}

Er werd een cross-sectioneel, internationaal onderzoek uitgevoerd bij volwassenen $\geq 18$ jaar door onderzoeksteams in Brazilië, Bulgarije, China, India, Ierland, Maleisië, Noord Macedonië, Singapore, Spanje, Turkije en de Verenigde Staten van Amerika (VS). In alle landen werd dezelfde valide en betrouwbare enquête afgenomen. Gegevens werden verzameld tussen 1 juni en 31 augustus 2020. Het artikel heeft ook informatie opgenomen over de onderzoeksopzet en de procedures die zijn gehanteerd.

\section{De enquête}

De enquête werd ontwikkeld in de VS [5] en uit dat land waren ook de studies over de impact van COVID19 op fysieke activiteit afkomstig [6, 7]. De enquête doorliep herhaalde reviewprocessen totdat tussen alle landen consensus over de vraagstelling was bereikt. Vervolgens werd in alle deelnemende landen een pilot gestart waaraan in totaal 131 respondenten deelnamen. De uiteindelijke enquête bevatte 73 vragen. De enquête werd door daartoe gecertificeerde vertalers vertaald in acht talen om tot een valide resultaat te komen.

\section{Procedure}

De enquêtes werden via een online platform (Qualtrics) anoniem verstuurd naar potentiële deelnemers. Respondenten die voldeden aan het inclusiecriterium $\geq 18$ jaar oud werden doorgestuurd naar additionele online informatie over de studie, waarna zij konden beginnen met het invullen van de daadwerkelijke vragenlijst.

In totaal werden 15.529 enquêtes ingevuld, waarvan er 3.754 ongeldig waren omdat ze onvolledig of onjuist waren ingevuld. De resterende 11.775 enquêtes konden voor deze studie worden gebruikt.

\section{Studievariabelen en metingen}

Fysieke activiteit werd gemeten met de International Physical Activity Questionnaire (IPAQ) (test-hertestbetrouwbaarheid $\geq 0,80[5]$ ). Vragen betroffen de frequentie (dagen per week) en tijdsduur (tijd per dag) van de fysieke activiteit van de respondenten. De onderzoekers wezen de respondenten vervolgens toe aan drie categorieën: 'onvoldoende actief', 'gemiddeld niveau van fysieke activiteit' en 'hoog niveau van fysieke activiteit'. Tevens werd aan respondenten gevraagd of zij tijdens de lockdown fysiek actiever waren geworden, of juist niet, en of het niveau waarop fysieke activiteit plaatsvond tijdens de lockdown gelijk was gebleven.

De locatie en wijze van fysieke activiteit tijdens lockdown werd beoordeeld aan de hand van vijf vragen: 1) de locatie van fysiek actief zijn (binnen versus buiten; thuis versus in de openbare ruimte), 2) met wie de respondent fysieke activiteit beoefende, 3) de
Tabel 1 Demografische karakteristieken en psychische symptomen van de deelnemers uit de 11 participerende landen $(n=11.775)$

\begin{tabular}{|c|c|c|}
\hline \multicolumn{2}{|l|}{ Karakteristieken } & \multirow{2}{*}{$\begin{array}{l}N(\%) \\
1.432(12,2)\end{array}$} \\
\hline Landen & Brazilië & \\
\hline & Bulgarije & $933(7,9)$ \\
\hline & China & $1.952(16,6)$ \\
\hline & India & $848(7,2)$ \\
\hline & lerland & $930(7,9)$ \\
\hline & Maleisië & $766(6,5)$ \\
\hline & Noord Macedonië & $804(6,8)$ \\
\hline & Singapore & $800(6,8)$ \\
\hline & Spanje & $962(8,2)$ \\
\hline & Turkije & $1.360(11,6)$ \\
\hline & Amerika & $988(8,4)$ \\
\hline \multirow[t]{3}{*}{ Geslacht } & vrouw & $7.498(63,7)$ \\
\hline & $\operatorname{man}$ & $4.170(35,4)$ \\
\hline & anders & $107(0,9)$ \\
\hline \multirow[t]{6}{*}{ Leeftijdsgroep } & $18-24$ & $3.560(30,3)$ \\
\hline & $25-34$ & $2.540(21,6)$ \\
\hline & $35-44$ & $2.369(20.1)$ \\
\hline & $45-54$ & $1.703(14,5)$ \\
\hline & $55-64$ & $1.111(9,4)$ \\
\hline & $\geq 65$ & $480(4,1)$ \\
\hline \multirow[t]{3}{*}{ Burgerlijke staat } & gehuwd & $5.179(44,0)$ \\
\hline & alleenstaand & $5.783(49,1)$ \\
\hline & anders & $813(6,9)$ \\
\hline \multirow[t]{4}{*}{ Opleiding } & middelbare school of lager & $2.679(22,8)$ \\
\hline & mbo & $1.681(14,3)$ \\
\hline & hbo & $4.281(36,4)$ \\
\hline & masteropleiding & $3.111(26,5)$ \\
\hline \multirow[t]{4}{*}{ Gezondheid voor COVID-19 } & uitstekend & $2.927(24,9)$ \\
\hline & heel goed & $5.083(43,2)$ \\
\hline & goed & $3.144(26,7)$ \\
\hline & redelijk & $621(5,3)$ \\
\hline \multirow{2}{*}{$\begin{array}{l}\text { Samenwonend met persoon } \\
\geq 65 \text { jaar tijdens lockdown }\end{array}$} & ja & $2.468(21,0)$ \\
\hline & nee & $9.307(79,0)$ \\
\hline \multirow{2}{*}{$\begin{array}{l}\text { Een kind in het huishouden } \\
\text { tijdens lockdown }\end{array}$} & ja & $3.720(31,6)$ \\
\hline & nee & $8.055(68,4)$ \\
\hline \multirow{3}{*}{$\begin{array}{l}\text { Vereist om het huis te verla- } \\
\text { ten voor het werk }\end{array}$} & fulltime & $2.091(17,8)$ \\
\hline & parttime & $2.202(18,7)$ \\
\hline & nee & $7.482(63,5)$ \\
\hline \multirow{2}{*}{$\begin{array}{l}\text { Psychische symptomen } \\
\text { tijdens de lockdown (gem., } \\
\text { SD) }\end{array}$} & angstscore & $56,4(9,7)$ \\
\hline & depressiescore & $52,2(9,7)$ \\
\hline
\end{tabular}

frequentie waarin een online programma werd gevolgd, 4) het aantal keren dat fysieke activiteit werd gebruikt als copingstrategie en 5) het aantal keren dat een respondent iemand anders had aangespoord om deel te nemen aan fysieke activiteiten.

Het risico dat COVID-19 met zich meebracht op nationaal niveau werd geanalyseerd aan de hand van twee variabelen: de stijging van het aantal bevestigde COVID-19-gevallen per miljoen inwoners zoals ver- 
Tabel 2 COVID-19-risicofactoren op landelijk niveau en fysieke activiteit tijdens lockdown bij de 11 deelnemende landen

\begin{tabular}{|c|c|c|c|c|c|c|c|c|c|c|c|}
\hline & \multicolumn{2}{|c|}{ Onvoldoende actief } & \multicolumn{4}{|c|}{ Niveau van fysieke activiteit } & \multicolumn{3}{|c|}{ Verandering in fysieke activiteit } & \multirow{2}{*}{$\begin{array}{l}\text { Verhoging } \\
\text { van CoVID- } \\
\text { gevallen }^{\mathrm{a}}\end{array}$} & \multirow{2}{*}{$\begin{array}{l}\text { Beleids- } \\
\text { reactie } \\
\text { regering }\end{array}$} \\
\hline & $\mathrm{Ja}$ & Nee & Geen & Laag & Gemiddeld & Hoog & Verhoging & $\begin{array}{l}\text { Geen ver- } \\
\text { andering }\end{array}$ & Verlaging & & \\
\hline & $N(\%)$ & $N(\%)$ & $N(\%)$ & $N(\%)$ & $N(\%)$ & $N(\%)$ & $N(\%)$ & $N(\%)$ & $N(\%)$ & $\begin{array}{l}\text { Populatie } \\
\text { per miljoen }\end{array}$ & $\begin{array}{l}\text { Gestandaar- } \\
\text { diseerde } \\
\text { score }\end{array}$ \\
\hline Brazilië & $834(58,2)$ & $598(41,8)$ & $481(33,6)$ & $353(24,7)$ & $270(18,9)$ & $328(22,9)$ & $239(16,7)$ & $343(24,0)$ & $800(55,9)$ & 106,3 & 75,6 \\
\hline Bulgarije & $197(21,1)$ & $736(78,9)$ & $83(8,9)$ & $114(12,2)$ & $290(31,1)$ & $446(47,8)$ & $75(8,0)$ & $448(48,0)$ & $400(42,9)$ & 14,0 & 51,7 \\
\hline China & $1064(54,5)$ & $888(45,5)$ & $618(31,7)$ & $446(22,9)$ & $405(20,8)$ & $483(24,7)$ & $329(16,9)$ & $844(43,2)$ & $779(39,9)$ & 0,3 & 73,3 \\
\hline India & $435(51,3)$ & $413(48,7)$ & $362(42,7)$ & $73(8,6)$ & $178(21,0)$ & $235(27,7)$ & $172(20,3)$ & $265(31,3)$ & $348(41,0)$ & 15,7 & 82,9 \\
\hline Ierland & $233(25,1)$ & $697(75,0)$ & $92(9,9)$ & $141(15,2)$ & $274(29,5)$ & $423(45,5)$ & $336(36,1)$ & $238(25,6)$ & $314(33,8)$ & 34,2 & 67,6 \\
\hline Maleisië & $423(55,2)$ & $343(44,8)$ & $265(34,6)$ & $158(20,6)$ & $123(16,1)$ & $220(28,7)$ & $129(16,8)$ & $258(33,7)$ & $379(49,5)$ & 1,6 & 61,6 \\
\hline $\begin{array}{l}\text { Noord } \\
\text { Macedonië }\end{array}$ & $240(29,9)$ & $564(70,2)$ & $99(12,3)$ & $141(17,5)$ & $163(20,3)$ & $401(49,9)$ & $152(18,9)$ & $326(40,6)$ & $324(40,3)$ & 40,8 & 65,5 \\
\hline Singapore & $342(42,8)$ & $458(57,3)$ & $140(17,5)$ & $202(25,3)$ & $188(23,5)$ & $270(33,8)$ & $241(30,1)$ & $352(44,0)$ & $207(25,9)$ & 52,9 & 60,5 \\
\hline Spanje & $411(42,7)$ & $551(57,3)$ & $213(22,1)$ & $198(20,6)$ & $252(26,2)$ & $299(31,1)$ & $198(20,6)$ & $202(21,0)$ & $524(54,5)$ & 54,4 & 65,3 \\
\hline Turkije & $604(44,4)$ & $756(55,6)$ & $289(21,3)$ & $315(23,2)$ & $342(25,2)$ & $414(30,4)$ & $206(15,2)$ & $350(25,7)$ & $804(59,1)$ & 19,1 & 64,2 \\
\hline Amerika & $386(39,1)$ & $602(60,9)$ & $138(14,0)$ & $248(25,1)$ & $307(31,1)$ & $295(29,9)$ & $222(22,5)$ & $328(33,2)$ & $394(39,9)$ & 100,1 & 66,8 \\
\hline Totaal & $\begin{array}{l}5169 \\
(43,9)^{b}\end{array}$ & $\begin{array}{l}6606 \\
(56,1)\end{array}$ & $\begin{array}{l}2780 \\
(23,6)\end{array}$ & $\begin{array}{l}2389 \\
(20,3)\end{array}$ & $\begin{array}{l}2792 \\
(23,7)\end{array}$ & $\begin{array}{l}3814 \\
(32,4)^{b}\end{array}$ & $\begin{array}{l}2522 \\
(21,4)\end{array}$ & $3175(27,0)$ & $5273(44,8)^{b}$ & 39,4 & $67,7^{c}$ \\
\hline
\end{tabular}

meld op de publiek toegankelijke site Our World in Data [8], en het overheidsbeleid als reactie op die stijging. Deze reactie werd bepaald door van elk land de Goverment Stringency Index (GSI) te berekenen. De GSI is een dagelijks samengestelde score tussen 0 en $100(0=$ 'geen beleidsrespons'; $100=$ 'de strengste beleidsrespons') die negen beleidsterreinen beslaat (waaronder sluiting van scholen, sluiting van werkplekken, reisverboden) [8].

Symptomen van angst en depressie werden gescoord op drie valide vragenlijsten: de Adult Patient-Reported Outcomes Measurement Information System $\left(\mathrm{PROMIS}^{\circledR}\right.$ ), de Short Form v1.0-Anxiety $4 a$ en de PROMIS ${ }^{\circledR}$ Short Form v1.0-Depression $4 a$ [9]. Ze bestaan alle drie uit vier vragen die de respondent moet scoren op een vijfpunts Likert-schaal (bereik 4 tot 20) waarbij een hogere score meer symptomen betekent. Data-analyse vond plaats op de $t$-scores van de ruwe scores [9].

De demografische variabelen waren geslacht, leeftijdsgroep, hoogste opleidingsniveau, burgerlijke staat, samenwonend met een persoon $\geq 65$ jaar, een kind in het huishouden, vereist om het huis te verlaten voor het werk en gezondheidstoestand voor COVID-19.

\section{Statistische analyse}

Met de chi-kwadraattoets werd berekend hoe de mate van fysieke activiteit, de locatie van de fysieke activiteit en de wijze waarop de fysieke activiteit werd uitgevoerd waren verdeeld over de respondenten. Welke factoren geassocieerd waren met de verhouding tus- sen respondenten die onvoldoende actief waren en respondenten die een verlaging van hun fysieke activiteit rapporteerden werden bepaald met hiërarchische regressieanalyse. De variatie tussen landen werd ingeschat met de intraclass correlatiecoëfficient (ICC). Het Akaike information criterion (AIC) en het Bayesian information criterion (BIC) werden gebruikt om de vorm van het model te bepalen en het null model om te werken tot full model [10].

\section{Resultaten}

Karakteristieken van deelnemers zijn opgenomen in tab. 1. De respondenten bestonden voor $63,7 \%$ $(n=7.498)$ uit vrouwen, $52,8 \% \quad(n=6.100)$ had een leeftijd tussen de 18 en 34 jaar, $62,9 \% \quad(n=7.392)$ had een hbo-opleiding of hoger genoten en $49,1 \%$ $(n=5.783)$ was vrijgezel. De gemiddelde score voor angst en depressie was respectievelijk 56,4 en 52,2.

\section{Fysieke activiteit tijdens lockdown op individueel niveau}

Meer dan $40 \%$ van de respondenten was onvoldoende actief tijdens lockdown (tab. 2). Ongeveer een derde behaalde een hoog niveau van fysieke activiteit en ongeveer een kwart een gemiddeld niveau. Bij meer dan $40 \%$ van de respondenten nam het niveau van fysieke activiteit tijdens lockdown af.

\section{Fysieke activiteit tijdens lockdown per land}

Tussen de landen werden significante verschillen waargenomen in de proportie deelnemers die onvol- 


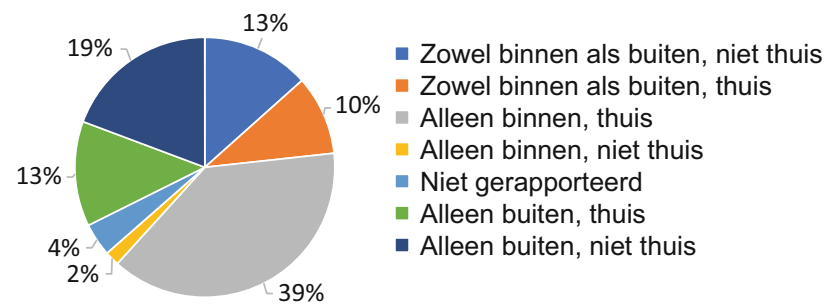

Figuur 1 Plaats waar fysiek actieve respondenten tijdens lockdown fysieke activiteiten uitvoerden $(n=8.995)$

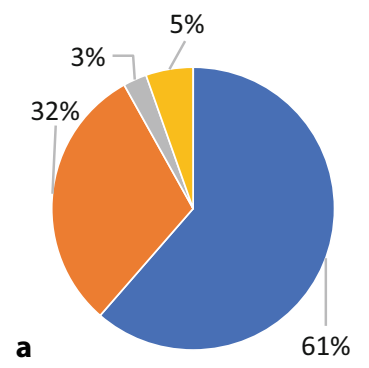

Zelfstandig
Met familieleden

Met familieleden en anderen

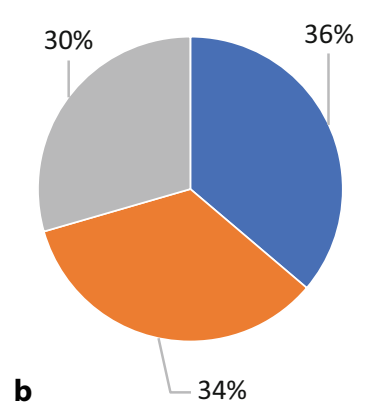

Nooit, bijna nooit
Soms, af en toe
Vaak, altijd

Nooit, bijna nooit

- Soms, af en toe

Vaak, altijd

Nooit, bijna nooit

Soms, af en toe

Vaak, altijd

d

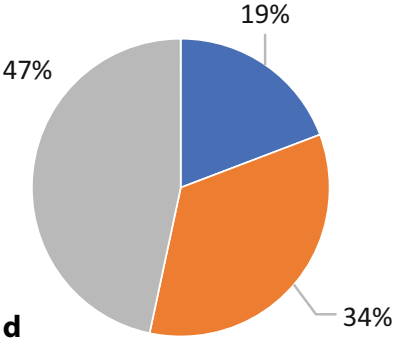

Figuur 2 Wijze waarop fysiek actieve respondenten tijdens lockdown fysieke activiteit uitvoerden $(n=8.995)$. a Personen die deelnemen aan fysieke activiteit. b Frequentie waarin online programma's worden gebruikt. c Frequentie waarin fysieke activiteit als copingstrategie wordt gebruikt. d De frequentie waarmee anderen worden aangemoedigd om deel te nemen aan fysieke activiteiten doende actief was $(p<0,0001)$, het niveau van fysieke activiteit $(p<0,0001)$ en verlaging van het niveau van die fysieke activiteit ( $p<0,0001)$ (tab. 2). Inwoners van Brazilië, Maleisië, China en India waren het meest inactief tijdens lockdown. De hoogste GSI-scores werden geobserveerd in India, Brazilië en China.

Locatie en wijze van fysieke activiteit tijdens lockdown $62 \%$ van de actieve deelnemers voerden de fysieke activiteit thuis uit, van wie 39\% alleen binnenshuis (fig. 1). 61\% deed de fysieke activiteit alleen, 64\% gebruikten online programma's, $47 \%$ spoorde anderen aan om fysieke activiteit te ondernemen en $72 \%$ gebruikten fysieke activiteit als copingstrategie (fig. 2).

\section{Factoren die zijn geassocieerd met fysieke activiteit} tijdens lockdown

Strengere overheidsmaatregelen vergrootten de kans op onvoldoende activiteit tijdens lockdown (tab. 3). Een verhoging van 5 punten op de GIS leidde tot $22 \%$ meer kans om onvoldoende fysiek actief te zijn tijdens lockdown. Ook hogere depressiescores leidden tot minder fysieke activiteit én een verlaging van het niveau waarop de fysieke activiteit plaatsvond. Dit laatste gold ook voor hogere angstscores. Vrouw zijn, een leeftijd $\geq 65$ jaar hebben, getrouwd zijn, een thuiswonend kind hebben tijdens lockdown en buitenshuis werken tijdens lockdown, leidden ook tot een verhoogde kans op onvoldoende fysiek actief zijn (tab. 3). Bij respondenten met een hbo- of masteropleiding en bij respondenten die voor de lockdown een uitstekende gezondheid hadden, was die kans juist lager.

\section{Discussie}

De belangrijkste bevindingen uit dit onderzoek laten zien dat tijdens een COVID-19-lockdown bij meer dan $40 \%$ van de deelnemers het niveau van fysieke activiteit onvoldoende was of was verminderd. Het niveau van de fysieke activiteit verschilde per land; inwoners van landen met strengere overheidsmaatregelen hadden een grotere kans op onvoldoende fysieke activiteit. Ook hogere depressie- en angstscores gingen gepaard met verlaging van het niveau van fysieke activiteit. Gezien de gezondheidsrisico's die gepaard gaan met onvoldoende fysieke activiteit zullen deze bevindingen belangrijke implicaties hebben voor de ontwikkeling en implementatie van stimuleringsprogramma's die zijn gericht op fysieke activiteit [11].

In landen met de strengste overheidsmaatregelen is de groep inactieve personen het grootst (Brazilië, Maleisië, China en India). Deze resultaten suggereren dat een COVID-19-lockdown en bijbehorende restricties de mogelijkheid van mensen om fysieke activiteit te beoefenen substantieel verlagen doordat bijvoorbeeld fitnesscentra, zwembaden en recreatieve buitenfaciliteiten gesloten worden [12].

Gezien de toename van mentale gezondheidsklachten tijdens lockdown en de mentale en gezondheids- 
Tabel 3 Factoren die verband houden met fysieke activiteit tijdens de lockdown

\begin{tabular}{|c|c|c|c|}
\hline \multirow[t]{2}{*}{ Factoren } & \multicolumn{2}{|l|}{ Onvoldoende actief } & \multirow{2}{*}{$\begin{array}{l}\text { Verlaging van fysieke activiteit } \\
\text { OR (95\%-BI) }\end{array}$} \\
\hline & & OR (95\%-BI) & \\
\hline \multirow{2}{*}{$\begin{array}{l}\text { COVID-19-risico op landelijk } \\
\text { niveau }\end{array}$} & 10 eenheden verandering van bevestigde gevallen & $0,97(0,90-1,05)$ & $0,98(0,92-1,04)$ \\
\hline & 5 eenheden wijziging van beleidsreactiescore & $1,22(1,03-1,45)$ & $1,01(0,88-1,15)$ \\
\hline \multirow{2}{*}{$\begin{array}{l}\text { Psychische symptomen tijdens } \\
\text { lockdown }\end{array}$} & 10 eenheden verandering van angstscore & $0,98(0,92-1,05)$ & $1,18(1,11-1,26)$ \\
\hline & 10 eenheden verandering van depressiescore & $1,44(1,07-1,22)$ & $1,15(1,08-1,22)$ \\
\hline \multirow[t]{2}{*}{ Geslacht $^{\mathrm{a}}$} & vrouw & $1,30(1,19-1,42)$ & $0,92(0,85-1,00)$ \\
\hline & man & referentie & referentie \\
\hline \multirow[t]{6}{*}{ Leeftijdsgroep } & $18-24$ & referentie & referentie \\
\hline & $25-34$ & $1,15(1,01-1,30)$ & $1,06(0,93-1,20)$ \\
\hline & $35-44$ & $1,16(0,99-1,36)$ & $1,19(1,03-1,39)$ \\
\hline & $45-54$ & $1,09(0,92-1,29)$ & $1,24(1,05-1,46)$ \\
\hline & $55-64$ & $0,98(0,81-1,18)$ & $1,37(1,14-1,64)$ \\
\hline & $\geq 65$ & $1,50(1,18-1,91)$ & $1,10(0,87-1,40)$ \\
\hline \multirow[t]{2}{*}{ Burgerlijke staat ${ }^{\mathrm{a}}$} & gehuwd & $1,15(1,02-1,31)$ & $0,98(0,87-1,11)$ \\
\hline & alleenstaand & referentie & referentie \\
\hline \multirow[t]{4}{*}{ Opleiding } & middelbare school of lager & referentie & referentie \\
\hline & mbo & $1,01(0,88-1,15)$ & $1,06(0,93-1,21)$ \\
\hline & hbo & $0,79(0,71-0,88)$ & $1,20(1,08-1,33)$ \\
\hline & masteropleiding & $0,79(0,70-0,89)$ & $1,30(1,16-1,47)$ \\
\hline \multirow[t]{4}{*}{ Gezondheid voor COVID-19 } & uitstekend & $0,34(0,28-0,41)$ & $1,00(0,83-1,20)$ \\
\hline & heel goed & $0,47(0,39-0,56)$ & $1,18(0,99-1,40)$ \\
\hline & goed & $0,72(0,59-0,86)$ & $1,17(0,97-1,40)$ \\
\hline & redelijk & referentie & referentie \\
\hline \multirow{2}{*}{$\begin{array}{l}\text { Samenwonend met persoon } \\
\geq 65 \text { jaar tijdens lockdown }\end{array}$} & ja & $0,96(0,86-1,06)$ & $0,93(0,84-1,03)$ \\
\hline & nee & referentie & referentie \\
\hline \multirow{2}{*}{$\begin{array}{l}\text { Een kind in het huishouden } \\
\text { tijdens lockdown }\end{array}$} & ja & $1,17(1,05-1,31)$ & $0,89(0,80-0,99)$ \\
\hline & nee & referentie & referentie \\
\hline \multirow{3}{*}{$\begin{array}{l}\text { Vereist om het huis te verlaten } \\
\text { voor het werk }\end{array}$} & fulltime & $1,16(1,04-1,30)$ & $0,91(0,81-1,01)$ \\
\hline & parttime & $1,03(0,93-1,14)$ & $1,00(0,90-1,11)$ \\
\hline & nee & & \\
\hline ICC (null model) & & 0,075 & 0,045 \\
\hline AIC (full model) & & $14.798,77$ & $15,369,79$ \\
\hline BIC (full model) & & $14.808,72$ & $15,379,73$ \\
\hline
\end{tabular}

voordelen van fysieke activiteit [7], is het door de WHO aanbevolen beweegadvies tijdens een lockdown nog belangrijker dan onder normale omstandigheden [13]. De bevindingen benadrukken het belang van goede overheidscommunicatie over het nut van fysieke activiteit als copingstrategie voor het omgaan met de psychologische last en negatieve emoties waarmee een lockdown gepaard gaat [13]. Meer dan $60 \%$ van de deelnemers deed thuis aan fysieke activiteit, $40 \%$ uitsluitend binnen en meer dan $60 \%$ deed dat alleen. Veel deelnemers gebruikten online programma's.

Tijdens de COVID-19-pandemie werden veel programma's ontwikkeld om mensen te helpen actief te blijven tijdens lockdown [14]. Dergelijke online programma's moeten de basis vormen voor toekomstige initiatieven op het gebied van fysieke activiteit en moeten worden verspreid via internet en de mainstream media [14]. De resultaten van deze studie ondersteunen de behoefte aan landspecifieke interventies op het gebied van fysieke activiteit die thuis en/of online te volgen zijn ter bevordering van fysieke activiteit, mocht zich opnieuw een pandemie voordoen.

Deze studie heeft vele sterke punten, zoals de inclusie van 11 deelnemende landen, de grote onderzoekspopulatie en goed ontworpen en geïmplementeerde onderzoeksprotocollen. Ze heeft echter ook beperkingen. Ten eerste werden de gegevens op een retrospectieve manier verzameld; daarom kunnen deze onderhevig zijn aan fouten. Ten tweede betreft het een cross-sectioneel onderzoek, dus er kan geen uitspraak worden gedaan over causaliteit. Ten derde waren de gegevens niet representatief voor de populatie in elk van de 11 landen. Zo waren de meeste deelnemers vrouw en waren de jongere leeftijdsgroepen oververtegenwoordigd en geen afspiegeling van de landelijke 
populatie. Ook werden de gegevens van deze studie verzameld terwijl elk land zich in een andere fase van lockdown bevond. De resultaten zijn dus mogelijk niet generaliseerbaar naar alle landen.

\section{Reflectie op het onderzoek}

De resultaten uit deze studie laten zien dat lockdown een negatief effect heeft op de fysieke activiteit van mensen. Mensen hebben minder mogelijkheden om te sporten, omdat sportlocaties noodgedwongen hun deuren moeten sluiten. Mensen raken sociaal geïsoleerd waardoor niet alleen gezondheidsklachten maar ook mentale gezondheidsklachten ontstaan. In Nederland gingen er naar mijn mening meer mensen wandelen waardoor we in de praktijk een verschuiving zagen van sportgerelateerde klachten naar meer wandelgerelateerde klachten, en bij ons in de praktijk zelfs een forse daling van het aantal groei- en sportgerelateerde klachten bij jonge adolescenten.

$\mathrm{Na}$ het lezen van dit artikel lijkt het mij aannemelijk dat ook een groot deel van de Nederlanders tijdens lockdown minder lichamelijk actief is. Waarschijnlijk is tevens de mentale gezondheid van mensen in Nederland achteruitgegaan. Aangezien wij tijdens lockdowns gewoon patiënten kunnen zien, lijkt het mij raadzaam om tijdens een lockdown naast het fysieke aspect van gezondheid, ook het mentale aspect ervan met onze patiënten te bespreken.

\section{Take home messages}

- De COVID-19-lockdown leidt bij veel mensen tot minder fysieke activiteit en tot een lager niveau van fysieke activiteit en bij velen tot een hoger niveau van depressie en angst.

- Hoe strenger de overheidsmaatregelen, hoe groter de kans op onvoldoende fysieke activiteit.

- Veel mensen gebruiken tijdens lockdown sport als copingstrategie.

\section{Literatuur}

1. Anderson RM, Heesterbeek H, Klinkenberg D, Hollingsworth TD. How will country-based mitigation measures influence the course of the COVID-19 epidemic? Lancet. 2020;395:931-4.
2. Brooks SK, Webster RK, Smith LE, et al. The psychological impact of quarantine and how to reduce it: rapid review of the evidence. Lancet. 2020;395:912-20.

3. Ashdown-Franks G, Sabiston CM, Stubbs B. The evidence for physical activity in the management of major mental illnesses: a concise overview to informbusy clinicians' practice and guide policy. Curr Opin Psychiatry. 2019;32:375-80.

4. World Health Organization. How to stay physically active during COVID-19 self-quarantine. http://www.euro. who.int/en/health-topics/disease-prevention/physicalactivity/news/news/2020/3/how-to-stayphysicallyactive-during-covid-19-self-quarantine. Geraadpleegd op: $25 \mathrm{mrt} 2021$.

5. Lee PH, Macfarlane DJ, Lam T, Stewart SM. Validity of the international physical activity questionnaire short form (IPAQ-SF): a systematic review. Int J Behav Nutr Phys Act. 2011;8:115.

6. Ahmad A, Mueller C, Tsamakis K. COVID-19 pandemic: a public and global mental health opportunity for social transformation? BMJ. 2020;369:m1383.

7. Shariat A, Cleland JA, Hakakzadeh A. Home-based exercises during the COVID-19 quarantine situation for office workers: a commentary. Work. 2020;66:381-2.

8. Our World in Data. COVID-19: stringency index.. https:// ourworldindata.org/grapher/covid-stringency-index. Geraadpleegd op: 25 mrt 2021.

9. Pilkonis PA, Choi SW, Reise SP, et al. PROMIS cooperative group item banks for measuring emotional distress from the patient-reported outcomes measurement information system (PROMIS ${ }^{\circledR}$ ): depression, anxiety, and anger. Assessment. 2011;18:263-83.

10. Merlo J, Yang M, Chaix B, et al. A brief conceptual tutorial on multilevel analysis in social epidemiology: investigating contextual phenomena indifferent groups of people. JEpidemiol Community Health. 2005;59:729-36.

11. Schuch FB, Bulzing RA, Meyer J, et al. Associations of moderate to vigorous physical activity and sedentary behavior with depressive and anxiety symptoms in self-isolating people during the COVID-19 pandemic: a cross-sectional survey in Brazil. Psychiatry Res. 2020;292:113339.

12. Castañeda-Babarro A, Arbillaga-Etxarri A, Gutiérrez-Santamaría B, Coca A. Physical activity change during COVID-19 confinement. Int JEnviron Res Public Health. 2020;17:6878.

13. Jacob L, Tully MA, BarnettY, et al. The relationship between physical activity and mental health in a sample of the UK public: a cross-sectional study during the implementation of COVID-19 social distancing measures. Ment Health Phys Act. 2020;19:100345.

14. Khoramipour K, Basereh A, Hekmatikar AA, et al. Physical activity and nutrition guidelines to help with the fight against COVID-19. JSports Sci. 2021;39:101-7.

Koen J.M. Spaninks, podotherapeut 